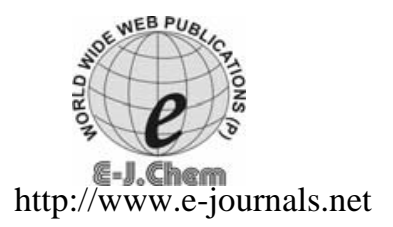

ISSN: 0973-4945; CODEN ECJHAO

E-Journal of Chemistry

2012, 9(1), 21-26

\title{
Conductometric Study of Nimesulide in Aqueous Solutions of Hydrotropic Agents at Different Temperatures
}

\author{
CHANDRAVIR S. SOLANKI, PARESH MISHRA, MAHESH KUMAR TALARI ${ }^{\S}$, \\ MINAKETAN TRIPATHY $^{*}$ and UPENDRA N.DASH ${ }^{\#}$ \\ Indira Gandhi Institute of Pharmaceutical Sciences \\ Nayapalli, Bhubaneswar, India \\ ${ }^{\S}$ Faculty of Applied Sciences, Universiti Teknologi MARA (UiTM) \\ Shah Alam, Selangor, 40450, Malaysia \\ *Faculty of Pharmacy, Universiti Teknologi MARA (UiTM) \\ Campus Puncak Alam, Selangor, 42300, Malaysia \\ "Department of Chemistry, ITER, Siksha 'O' Anusandhan University \\ Bhubanesawr, 751030, India \\ minaketan@salam.uitm.edu.my
}

Received 4 August 2010; Revised 20 October 2010; Accepted 28 December 2010

\begin{abstract}
Conductance values of nimesulide have been determined in water in $0.1,0.2,0.4,0.6,0.8,1$ and $2 \mathrm{~mol} \mathrm{dm}^{-3}$ aqueous solutions of hydrotropic agents (sodium benzoate, sodium salicylate, sodium bromide and nicotinamide) at temperatures 298.15, 303.15, 308.15 and $313.15 \mathrm{~K}$. The conductance values have been used to evaluate the limiting molar conductance and association constants by means of Shedlovsky extrapolation technique. Thermodynamic parameters for the association process of nimesulide in aqueous solutions of hydrotropic agents have also been calculated.
\end{abstract}

Keywords: Nimesulide, Hydrotropic agents, Limiting molar conductance, Association constants, Walden product

\section{Introduction}

Solubility and permeability are the two key biopharmaceutical parameters responsible for effective bioavailability and good in vitro and in vivo correlation ${ }^{1}$. Enhancement of solubility and dissolution rate and oral bioavailability of poorly water soluble drugs are still the challenging aspects for the pharmaceutical technologists ${ }^{2}$. Hydrotropic solubilisation is considered as one of the safest methods of solubilisation ${ }^{3}$. Aqueous solubilisation of insoluble 
drugs can be achieved by addition of hydrotropic agents. Many work highlighted the effect of the solubility enhancers (hydrotropic agents) ${ }^{4,5}$ and hence improved solubility of the drug, but no detailed explanation is available relating to the improvement phenomenon. Recently, we have reported volumetric and viscometric studies on nimesulide in aqueous solutions of four different hydrotropic agents (sodium benzoate, sodium salicylate, sodium bromide and nicotinamide) at different temperatures, so as to highlight the solute-solvent interactions correlating the solubility findings ${ }^{6}$. Conductometric studies of solutes at definite and infinite dilution in a solvent system provide valuable information regarding the ion-ion and ionsolvent interactions. By examining the limiting molar conductivity $\left(\Lambda_{0}\right)$, association constant $\left(\mathrm{K}_{\mathrm{A}}\right)$, Walden products $\left(\Lambda_{0} \eta_{0}\right)$ of ionic solutions as a function of size, nature, temperature and composition of the solvent, it is possible to examine the parameters on solute-solvent interaction with the hope of obtaining a better understanding of interactions in solutions ${ }^{7}$. The present study aimed to highlight the solute (drug nimesulide) - solvent (water) interactions and related modifications in case of the presence of hydrotropic agents at different temperatures.

\section{Experimental}

Sodium benzoate, sodium salicylate, sodium bromide and nicotinamide were of analytical reagents and kept in a vacuum desiccator over anhydrous $\mathrm{CaCl}_{2}$ until required. Nimesulide was a gift sample (procured from M/S Alkem Laboratory, Mumbai, India) and used as such. The solutions were prepared freshly by mass using a metler balance with a precision of $\pm 0.01 \mathrm{mg}$ in doubly distilled deionized and degassed water and conversion of molality to molarity was done by standard expression ${ }^{8}$.

A conductivity meter with accuracy of $\pm 0.5 \%$ and a conductivity cell (Model -ELICO, India) were used for the measurement of conductivity of each sample. The conductance cell was equipped with a water circulating jacket and the temperature was controlled within $\pm 0.02 \mathrm{~K}$ with a water thermostat. The cell constant is $1.01 \mathrm{~cm}^{-1}$ which was calculated by repeated measurements of $\mathrm{KCl}$ solutions. All data were corrected with specific conductivity of pure water at the experimental temperatures.

Different concentrations ( 0.1 to $2.0 \mathrm{M})$ of each of the hydrotropic agents (sodiumbenzoate, sodium salicylate, sodium bromide and nicotinamide) were prepared separately in double distilled water using $100 \mathrm{~mL}$ conical flask and excess amount of drug, nimesulide was added to each flask containing the required molar solutions of the corresponding hydrotropic agents. All the conical flasks were put in a mechanical shaker maintained at the required temperature within an accuracy of $\pm 0.02 \mathrm{~K}$ and shaken for a maximum period of $6 \mathrm{~h}$. The solutions were filtered and the specific conductivities were measured. The different molar solutions of hydrotropic agents without the drug were also measured for the specific conductivities. For each sample six data points were considered to calculate the average, which was further used to calculate the equivalent conductance for the samples.

\section{Results and Discussion}

The experimental data of the conductance measurements for the aqueous solutions of sodium benzoate, sodium salicylate, sodium bromide and nicotinamide with and without nimesulide after solvent correction were analyzed using Shedlovsky ${ }^{9}$ and Fuoss-Kraus ${ }^{10,11}$ extrapolation. As the limiting molar conductivity values, $\Lambda_{0}$ obtained by two methods using the values of ion-size parameter, $\mathrm{a}_{0}=0, \mathrm{q}$ and $2 \mathrm{q}$ are very close to each other, as presented else where ${ }^{7}$, the values of the $\Lambda_{0}$ for $\mathrm{a}_{0}=\mathrm{q}$ (but for nicotinamide $\mathrm{a}_{0}$ is taken as 0 ) are given 
in Table 1 for the Shedlovsky method only and so also the values of $\mathrm{K}_{\mathrm{A}}$, the association constants of hydrotropic agents and also of nimesulide in aqueous solutions of hydrotropic agents at experimental temperatures. It is noted that the obtained $\Lambda_{0}$ values of the hydrotropic agents in water are in good agreement with the values that are available in the literature $^{12}$.

Table 1. The values of limiting molar conductance $\Lambda_{0}\left(\mathrm{~S} \mathrm{~cm}^{2} \mathrm{~mol}^{-1}\right)$, association constant, $\mathrm{K}_{\mathrm{A}},\left(\mathrm{dm}^{3} \mathrm{~mol}^{-1}\right)$ and Walden product $\Lambda_{0} \eta_{0}$, (Wod = without drug; $\mathrm{Wd}=$ with drug $)$

\begin{tabular}{|c|c|c|c|c|}
\hline Sodium Benzoate & $\mathrm{T} / \mathrm{K}$ & $\Lambda_{0}$ & $\mathrm{~K}_{\mathrm{A}}$ & $\Lambda_{0} \eta_{0}$ \\
\hline Wod & 298.15 & 145.2 & 4.97 & 129.78 \\
\hline Wd & 298.15 & 100.5 & 12.11 & 89.77 \\
\hline Wod & 303.15 & 156.7 & -1.91 & 125.43 \\
\hline $\mathrm{Wd}$ & 303.15 & 117.5 & -1.07 & 94.04 \\
\hline Wod & 308.15 & 173.7 & -2.44 & 125.48 \\
\hline $\mathrm{Wd}$ & 308.15 & 128.7 & -2.49 & 92.96 \\
\hline Wod & 313.15 & 190.6 & 1.12 & 125.03 \\
\hline Wd & 313.15 & 146.4 & -1.09 & 96.02 \\
\hline Sodium Salicylate & $\mathrm{T} / \mathrm{K}$ & $\Lambda_{0}$ & $\mathrm{~K}_{\mathrm{A}}$ & $\Lambda_{0} \eta_{0}$ \\
\hline Wod & 298.15 & 146.5 & -3.76 & 130.90 \\
\hline $\mathrm{Wd}$ & 298.15 & 99.9 & -1.23 & 89.25 \\
\hline Wod & 303.15 & 157.1 & 21.91 & 125.80 \\
\hline $\mathrm{Wd}$ & 303.15 & 115.8 & 18.08 & 92.70 \\
\hline Wod & 308.15 & 177.0 & 10.09 & 127.91 \\
\hline Wd & 308.15 & 127.3 & 31.98 & 91.98 \\
\hline Wod & 313.15 & 193.7 & 11.48 & 127.06 \\
\hline Wd & 313.15 & 144.4 & 62.45 & 94.74 \\
\hline Sodium Bromide & $\mathrm{T} / \mathrm{K}$ & $\Lambda_{0}$ & $\mathrm{~K}_{\mathrm{A}}$ & $\Lambda_{0} \eta_{0}$ \\
\hline Wod & 298.15 & 228.9 & 15.71 & 204.57 \\
\hline $\mathrm{Wd}$ & 298.15 & 145.3 & -17.09 & 129.86 \\
\hline Wod & 303.15 & 239.7 & 16.24 & 191.90 \\
\hline $\mathrm{Wd}$ & 303.15 & 168.5 & -2.68 & 134.95 \\
\hline Wod & 308.15 & 257.7 & 17.45 & 186.17 \\
\hline $\mathrm{Wd}$ & 308.15 & 188.6 & 14.80 & 136.24 \\
\hline Wod & 313.15 & 288.1 & 15.75 & 189.01 \\
\hline Wd & 313.15 & 206.9 & 1.39 & 135.74 \\
\hline Nicotinamide & $\mathrm{T} / \mathrm{K}$ & $\Lambda_{0}$ & $\mathrm{~K}_{\mathrm{A}}$ & $\Lambda_{0} \eta_{0}$ \\
\hline Wod & 298.15 & 180.5 & -53.19 & 161.30 \\
\hline $\mathrm{Wd}$ & 298.15 & 153.4 & -20.77 & 137.10 \\
\hline Wod & 303.15 & 194.9 & -55.39 & 156.10 \\
\hline $\mathrm{Wd}$ & 303.15 & 123.2 & -25.05 & 98.64 \\
\hline Wod & 308.15 & 212.9 & -56.12 & 153.79 \\
\hline $\mathrm{Wd}$ & 308.15 & 117.9 & -25.60 & 85.17 \\
\hline Wod & 313.15 & 232.3 & -56.47 & 152.41 \\
\hline $\mathrm{Wd}$ & 313.15 & 120.28 & -26.06 & 78.90 \\
\hline
\end{tabular}


As observed, the values of $\Lambda_{0}$ of nimesulide in aqueous solutions of hydrotropic agents are very low. This is due to the fact that the hydrodynamic radii of the ions (generated from the hydrotropic agents) increase in the presence of nimesulide in the solution which causes a decrease in their mobility ${ }^{13}$.

It is evident from Table 1 that the values of $\Lambda_{0}$ of nimesulide increase with increase in temperature in the aqueous solutions of sodium benzoate, sodium salicylate and sodium bromide but decrease in the aqueous solutions of nicotinamide. The increased $\Lambda_{0}$ values with increase in temperature indicate less solvation or higher mobility of ions, which can be attributed to the fact that the increased thermal energy results in greater bond breaking and variation in vibrational, rotational and translational energy of the molecules that lead to higher frequency and higher mobility of the ions ${ }^{7}$. But the reverse is the case in the solutions of nicotinamide where the $\Lambda_{0}$ value decreases with increase in temperature and that can be attributed to the increased solvation and hydrodynamic radii of the ions there by decreasing the mobility. As observed, the values of $\Lambda_{0}$ of sodium bromide and also of nimesulide in solutions of sodium bromide are higher as compared to others. This is reasonable in view of the difference in transport properties of the hydrated bromide which reflects factors affecting its effective size and the strength of the coulombic field in the range of the hydration shell. The higher $\Lambda_{0}$ values in the solutions of sodium bromide are consistent with the lower viscosity values and lower solubility of nimesulide in sodium bromide solutions.

The variation of the Walden product, $\Lambda_{0} \eta_{0}$ (Table 1 ) is somewhat complex. The variation in the values of $\Lambda_{0} \eta_{0}$ indicates variation in the ionic radii and mobility of the ions due to varying degree of the ion-solvation in solution. The smaller $\Lambda_{0} \eta_{0}$ of the systems in nicotinamide solutions may be due to its large effective radius (due to large molecular aggregates) as compared to other systems.

A perusal of Table 1 shows that the association constant values are negative in the nicotinamide solutions at all the experimental temperatures and at certain temperatures in the solutions of sodium benzoate, sodium salicylate and sodium bromide. The negative association constant values in nicotinamide solutions are consistent with the result obtained from the lower $\Lambda_{0}$ values due to the formation of molecular aggregates in solution. This is also the case in the solutions of sodium benzoate, sodium salicylate and sodium bromide at certain temperatures where the molecular aggregates predominate over the ion pair formation. These findings are well supported by the previous research reports, which stated molecular aggregation being the mechanism of solubility enhancement of poorly soluble drugs in presence of hydrotropic agents ${ }^{14-16}$.

Since the conductance measurements of an ion depend upon mobility, it is quite reasonable ${ }^{17}$ to treat the conductance data similar to the one employed for the rate process taking place with the change of temperature, i.e,

$$
\Lambda_{0}=\text { A e-Es/RT Or } \log \Lambda_{0}=\log \text { A-Es/2.303RT }
$$

Where $\mathrm{A}$ is the frequency factor, $\mathrm{R}$ is the gas constant and Es is the arrhenius activation energy of the transport process. From the plot of $\log \Lambda_{0} v s .1 / \mathrm{T}$, the Es values have been computed from the slope (=-Es/2.303 R) and are recorded in Table 2. The free energy change, $\Delta \mathrm{G}_{0}$ for the association process is calculated from.

$$
\Lambda \mathrm{G}_{0}=-\mathrm{RT} \ln \mathrm{K}_{\mathrm{A}}
$$

The heat of association $\Delta \mathrm{H} 0$ is calculated from the slope of the plot of $\ln \mathrm{K}_{\mathrm{A}} v s 1 / \mathrm{T}$ and the entropy change, $\Delta \mathrm{S}_{0}$ from Gibbs - Helmholtz equation, 


$$
\Delta \mathrm{G}_{0}=\Delta \mathrm{H}_{0}-\mathrm{T} \Delta \mathrm{S}_{0}
$$

The values of $\Delta \mathrm{G}_{0}, \Delta \mathrm{H}_{0}$ and $\Delta \mathrm{S}_{0}$ at $298.15 \mathrm{~K}$ are given in Table 2. It can be seen from Table 2 that the values of ES are positive. The negative $\Delta G_{0}$ values for the systems of sodium benzoate with and without nimesulide and sodium bromide without nimesulide indicate that the association process predominates over the dissociation process. The negative $\Delta \mathrm{H}_{0}$ values for the systems containing sodium salicylate and sodium bromide with and without nimesulide show that the association processes are exothermic. The values of $\Delta \mathrm{S}_{0}$ are found to be positive in cases of sodium benzoate with and without, nimesulide and of sodium salicylate with nimesulide. The positive $\Delta \mathrm{S}_{0}$ values indicate the ions are hydrated in these systems.

Table 2. Thermodynamic parameters, $\Delta \mathrm{G}^{0}\left(\mathrm{~kJ} \mathrm{~mol}^{-1}\right), \Delta \mathrm{H}^{0}\left(\mathrm{~kJ} \mathrm{~mol}^{-1}\right), \Delta \mathrm{S}^{0}\left(\mathrm{~kJ} \mathrm{~mol}^{-1} \mathrm{~K}^{-1}\right)$ and $\mathrm{ES}(\mathrm{kJ} \mathrm{mol}-1)$ at $298.15 \mathrm{~K}$

\begin{tabular}{ccccc}
\hline \multicolumn{5}{c}{ Without drug } \\
\hline System & $\Delta \mathrm{G}^{0}$ & $\Delta \mathrm{H}^{0}$ & $\Delta \mathrm{S}^{0}$ & $\mathrm{ES}$ \\
Sodium Benzoate & -28.32 & 36.2 & 0.2 & 14.23 \\
Sodium Salicylate & 57.02 & -137.1 & -0.7 & 14.84 \\
Sodium Bromide & -89.53 & -154.8 & -0.2 & 11.79 \\
Nicotinamide & 303.13 & 360.7 & 0.2 & 13.09 \\
\multicolumn{5}{c}{ With drug } \\
Solution System & $\Delta \mathrm{G}^{0}$ & $\Delta \mathrm{H}^{0}$ & $\Delta \mathrm{S}^{0}$ & $\mathrm{ES}$ \\
Sodium Benzoate & -69.02 & 99.0 & 0.6 & 18.96 \\
Sodium Salicylate & 57.00 & -129.8 & 0.6 & 18.65 \\
Sodium Bromide & 97.45 & -248.7 & -1.0 & 18.22 \\
Nicotinamide & 118.37 & 132.2 & -0.5 & 12.16 \\
\hline
\end{tabular}

\section{Conclusion}

In this study conductivities for the (hydrotropic agents + water with or without nimesulide) systems were determined at the temperature range between 298.15 and $313.15 \mathrm{~K}$. The limiting molar conductivities of nimesulide are low in aqueous solutions of hydrotropic agents. These suggest that the studied hydrotropes form molecular aggregates in aqueous solutions. The variation in the values of Walden product $\left(\Lambda_{0} \eta_{0}\right)$ indicates variation in the ionic radii and mobility of ions due to varying degree of ion solvations in solutions. The non-constant Walden product in all the systems is expected due to highly viscous nature of the aqueous solutions of the hydrotropes with or without nimesulide and also due to the formation of the molecular aggregates.

\section{References}

1. Chakraborty S, Shukla D, Jain A, Mishra B and Singh S, J Coll Int Sci., 2009, 335, 242-249.

2. Pouton C W, Euro J Pharm Sci., 2006, 29, 278-287.

3. Drug information for health care professional, $17^{\text {th }}$ Ed., USPDI, 1997, 1646.

4. Agrawal S, Pancholi S S, Jain N K and Agrawal G P, Int J Pharm., 2004, 274,149-155.

5. Poochkian G D and Gradock J C, J Pharm Sci., 1974, 68, 728-732.

6. Solanki C S, Tripathy S, Tripathy M K and Dash U N, E- J Chem., 2010, 7(5), S223S230. 
7. Dash U N, Mohapatro J R and Lal B, J Mol Liq., 2006, 124, 13.

8. Robinson R A and Stokes R H, Electrolyte solutions; Butterworth Publications London, 1955, 30.

9. $\quad$ Shedlovsky T and Kay R L, J Phys Chem., 1956, 60, 151.

10. Fuoss R M, J Phys Chem., 1975, 79, 525.

11. Fuoss R M, J Phys Chem., 1978, 82, 2427.

12. Harned H S, Owen B B, The physical chemistry of electrolyte solutions; $3^{\text {rd }}$ Edn., Reinhold: Newyork, 1958, 358-370.

13. Singh R D, Rastogi P P and Gopal R, Can J Chem., 1968, 46, 3525.

14. Badwan A A, El-Khordagui L K, Saleh A M and Khalil S A, Int J Pharm., 1982, 13, 67-74.

15. Saleh A M and El-Khordagui L K, Int J Pharm., 1985, 24, 231-236.

16. Neuber C, J Pharm Sci., 1989, 75(7), 577.

17. Coetzee J F and Ritchi C D, Solute solvent interactions; Marcell Dekkar: Newyork and Basel, 1976. 


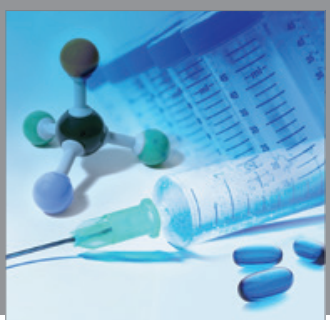

International Journal of

Medicinal Chemistry

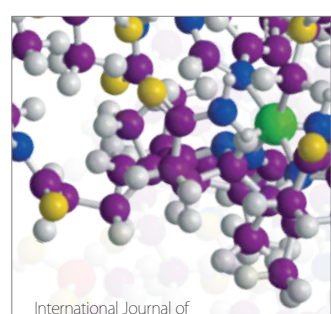

Carbohydrate Chemistry

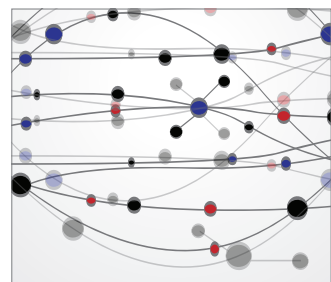

The Scientific World Journal
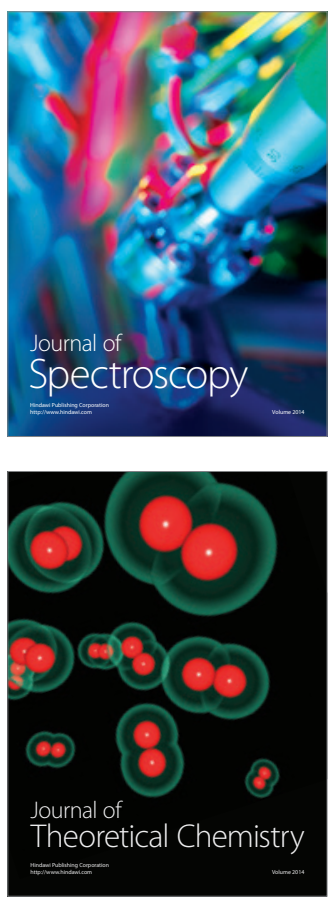
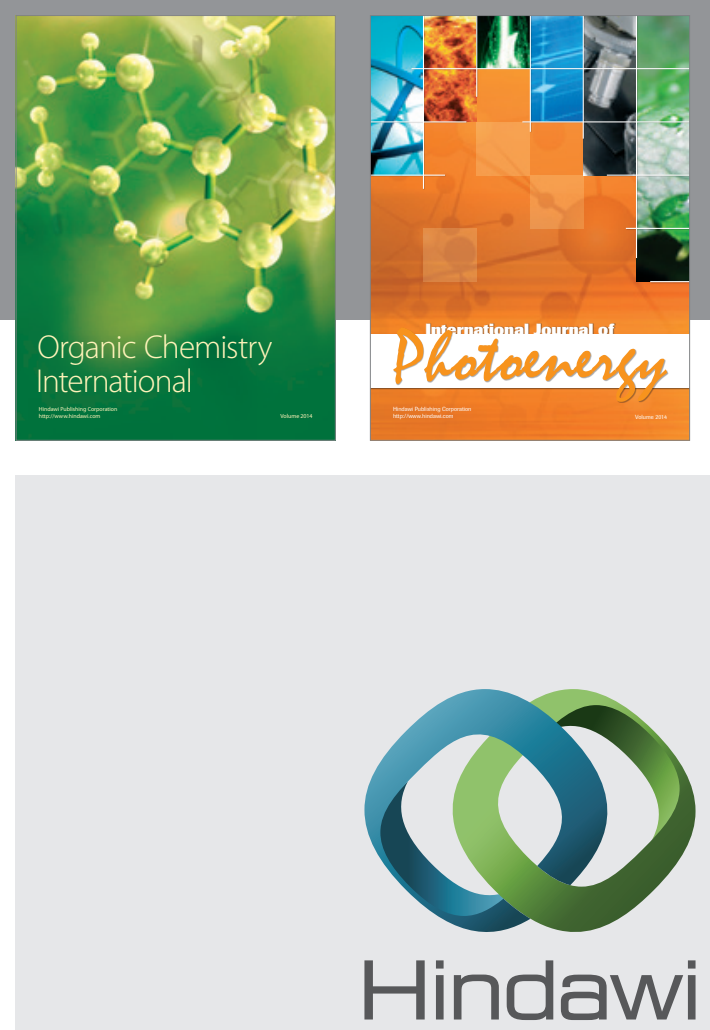

Submit your manuscripts at

http://www.hindawi.com
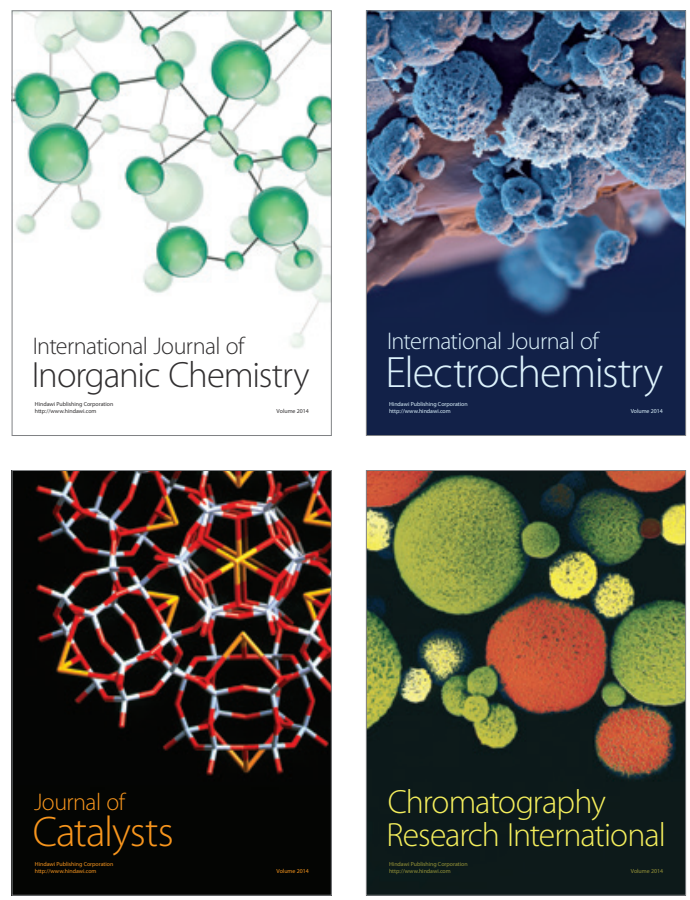
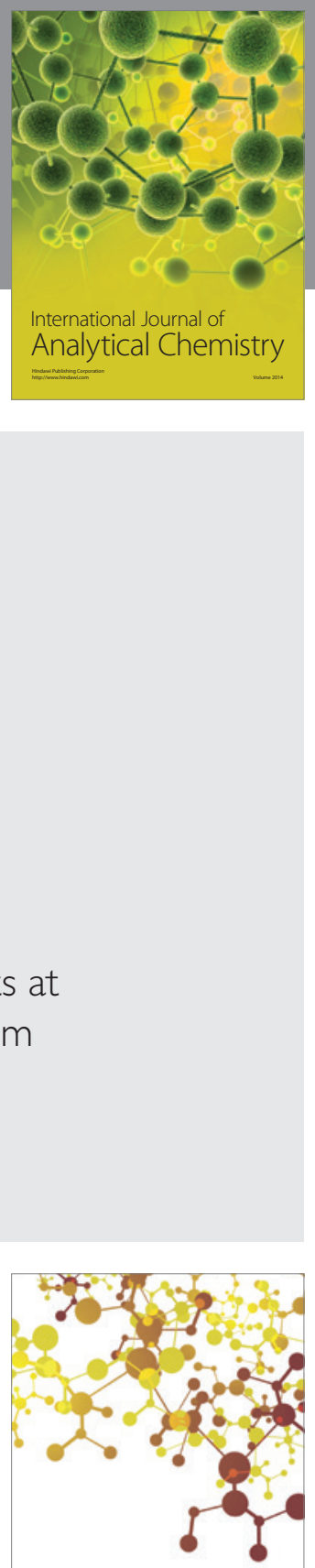

Journal of

Applied Chemistry
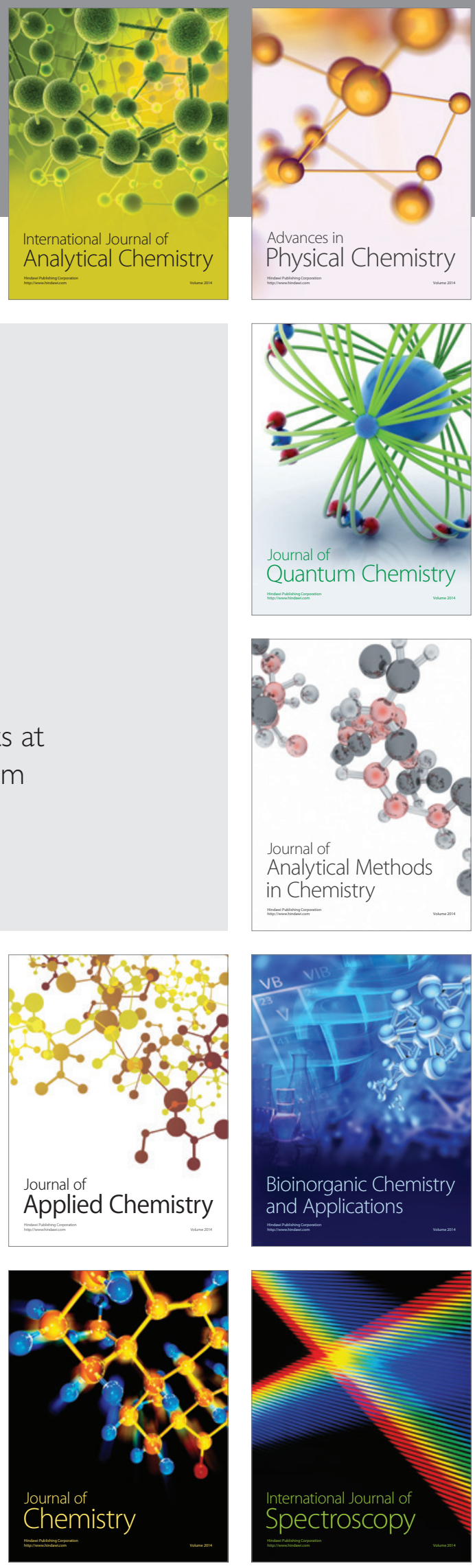